\title{
Commercial Announcements
}

\section{Data Aquisition and Analysis}

Discovery software automates data acquisition, transformation and reduction. Included in the package are commonly used data transformation and signal processing calculations such as integration, differentiation, autocorrelation, smoothing, windowing, calculation of area under a curve, range, variance, mean, standard deviation, slope and FFT. Runs on an IBM PC with a hard disk.

Cyborg Corp., 55 Chapel Street, Newton, MA 02158, U.S.A. (617) 964-9020.

\section{Data Collection, Display, Editing}

Insight provides for automatic collection, display and graphic comparison of input from chromatographs, mass spectrometers, scintillation counters, NMR and ESR spectrometers and spectrophotometers. This interactive, menudriven system for VAX computers allows data points to be displayed on the screen and edited interactively, and permits removal of anomalous data points.

Chesapeake Software Inc., Brandywood Plaza, Suite 221, 2500 Grubb Road, Wilmington, DE 19810, U.S.A. (302) $475-5229$.

\section{Chemical Directory on Optical Disk}

Fraser Williams: The Fine Chemicals Directory, a rapid means of locating American or European suppliers of any chemical or compound needed for research, is now available on compact optical disk (CDROM). The yearly subscription includes the data base and MicroBASIS* search and retrieval software, a user's guide, software documentation, two updates, a supplementary manual and telephone support. Part of Digital Equipment Corporation's CDROM Database Publications series, the Chemicals Directory optical disk can be read on a CD Reader manufactured by Digital for the MicroVAX I and II, VAXstation II, IBM PC, IBM PC-AT and IBM PC-XT computers (MSDOS V2.10 or later). Contact your local Digital sales office or call (800) 343-4040 for technical assistance or Fast Order Hotline at (800) 258-1710 for more information on both the CD Reader and the Chemicals Directory. A CD Reader for the Rainbow personal computer is available from Tecmar, Inc.; call (216) 349-0600 for further information. The cost of the CD Reader is under $\$ 2300$, and the cost of the data base under $\$ 1200$. The optical disks are in UNI-FILE format, developed by Digital specifically to ensure optical disk compatability among different computer systems. The use of UNI-FILE guarantees that the same optical disk will work on all of the computers listed above. Lotus Development Corporation, 3M Corporation and Tecmar Inc. have announced support of the UNI-FILE standard. The optical disk adheres to the Philips/Sony recording standard.

\footnotetext{
* MicroBASIS is a trademark of Battelle Development Corporation. VAX is a registered trademark of Digital Equipment Corp. IBM, IBM PC-AT and IBM PC-XT are registered trademarks of International Business Machines Corporation. MS is a trademark of Microsoft Corporation.
}

\section{Handbook of Sample Preparation and Handling}

A new Handbook of Sample Preparation and Handling for spectroscopy has been published by Spex Industries, Inc. of Edison, N.J. The 120-page handbook addresses many of the problems encountered with inhomogeneous or otherwise unmanagable samples prior to spectroscopic analysis. Techniques, helpful hints, and useful tricks are contained as well as a complete list of the company's products. Section 1 is devoted to three facets of sample preparation: pulverizing and blending, pressing and pelletizing, and flux fusion. The second section describes techniques and products, by field of spectroscopy including XRF, optical emission, fluorescence, and Raman spectroscopy.

Spex Industries Inc., 3880 Park Ave., Edison, N.J. 08820, U.S.A. 1-800-522-7739 or 201-549-7144.

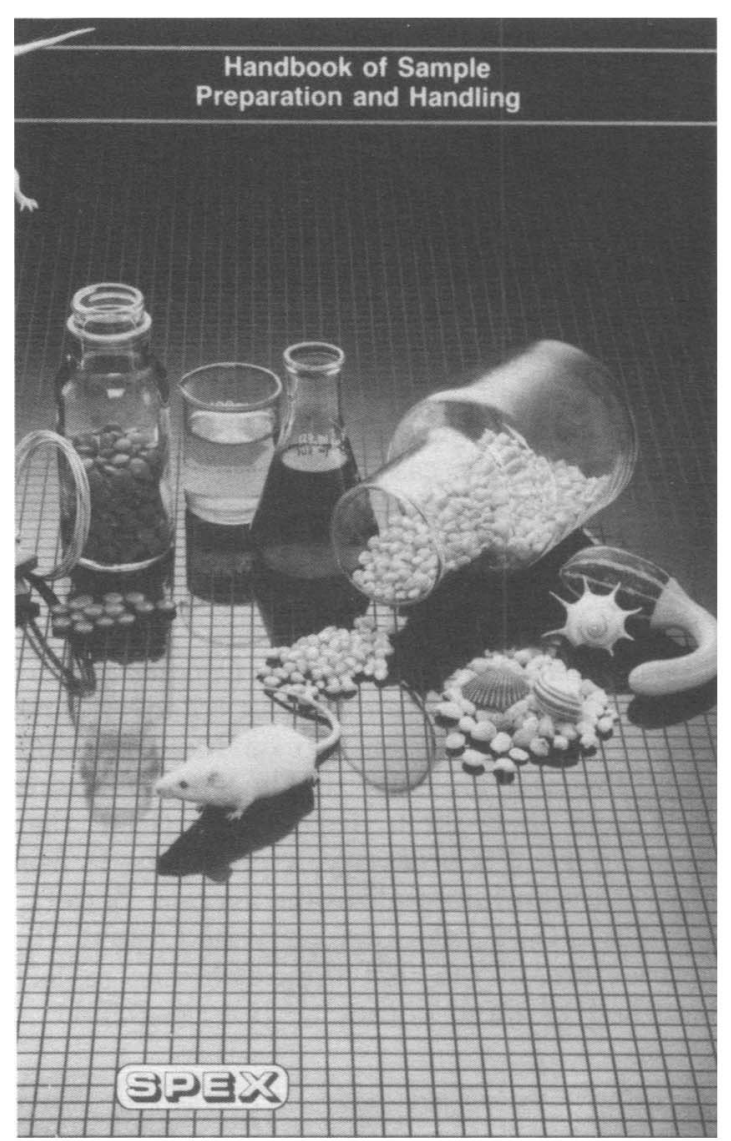




\section{American Crystallographic Association Application for Membership}

Any person actively interested in the study of the interatomic arrangement of matter, its causes, its nature and its consequences or the tools and methods used in such study, whose application is seconded by two regular, (not student) members of the Society, may become a member on payment of $\$ 25.00$ annual dues. Dues for students during the period of their studies are $\$ 7.50$ a year. In order to qualify for this rate a student must obtain the signature of a member of his teaching staff in the space provided below. Dues for corporation members are $\$ 125.00$ a year. Annual dues for retired members are $\$ 5.00$. Any member who has retired from regular employment will be classed as a member emeritus (retired member) upon notifying the Treasurer of the ACA of retirement. A retired member shall retain all the rights of membership. Application blanks may be obtained from the Secretary. Full membership privileges for the calendar year in which the payment of dues is made are extended to new members insofar as is possible. However, back issues of Physics Today that are missed in the year in which the member joins are not supplied.

Any person who joins the Society after June 30 of any year may elect to have his membership start on January 1 of the following year and should indicate here on his application whether he desires membership for the current year or for the following year. Membership desired for the Year

\section{Please Type or Print Name and Address}

(Name in proper form: Mr., Dr., Prof., Mrs., Miss, etc.)

(Date)

(Position)

(Firm or institution: address, including zip code)

\section{Home mailing address, including zip code}

Check preferred mailing address:

Home

Business

I am interested in membership in the Special Interest Group on:

Applied Crystallography

Biological Macromolecules

Small Angle Scattering

Small Molecule

Neutron Scattering

Signature of regular members

seconding the application:

(1)

(2)

Signature of member of teaching staff,

certifying that the applicant is a student:

(Title)

Send application with check for annual dues payable to the order of American Crystallographic Association to:

Mrs. Ethel E. Snider

Membership Secretary, ACA

American Institute of Physics

335 East 45 Street

New York, N.Y. 10017, U.S.A.

All checks must be drawn on United States Banks. 


\title{
850 new patterns
}

\section{0 patterns total 2700 species}

\author{
Data Book \\ - Enlarged and revised for Sets 1-35 \\ - Ordered alphabetically on mineral name \\ Search Manual contains sections on \\ - Chemical Name \\ - Hanawalt Numerical \\ - Fink Numerical \\ - Mineral Name
}

Since its inception almost 50 years ago, the Powder Diffraction File has always been well served in the area of mineral species. In 1974 the first special mineral based publication was produced, this being in the form of a book of minerals containing about 2,600 selected patterns in numerical sequence. A supplement to this edition was produced in 1981 . In 1980 an alphabetically ordered data book was produced followed by a group data book in 1983. Each of these products has proven very popular both with the community of mineralogists as well as others involved in general qualitative phase identification.

The International Centre for Diffraction Data is now pleased to announce a new Mineral Powder Diffraction File containing about 2,700 species represented by 3,400 patterns. This selection includes about 850 new patterns added since 1980. This revision of the mineral file has been produced by the Editors of the International Centre for Diffraction Data in cooperation with the Minerals Subcommittee, and has been further guided by nomenclature recommendations of the International Mineralogical Association.
The Mineral Powder Diffraction File Data Book is ordered alphabetically on mineral name, thus grouping together patterns of the same mineral including hydrates, polytypes, order-disorder and chemical varieties, and obviating the need for an index. All data have been reedited with special reference to nomenclature, chemical formula, indexing and other crystallographic data. Physical data is also recorded including opaque optical data where available.

The Search Manual supplied with the new Data Book is based on the latest Hanawalt search/matching techniques including special provisions for finding patterns recorded using the Debye-Scherrer technique and data from highly oriented materials.

We feel that with the large number of new patterns, along with the improved quality of many of the older data, this new product should prove invaluable to both existing users of the Mineral Data products as well as to those new to the field.

Price: $\$ 550.00 \quad$ Terms: Domestic -30 days net Foreign - Prepayment in U.S. currency

Please address all inquires and orders to:

JCPDS - International Centre for Diffraction Data 1601 Park Lane

Swarthmore, Pennsylvania 19081

U.S.A.

Telephone: (215) 328-9400

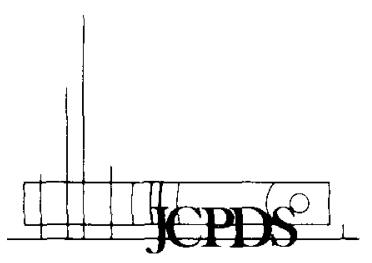

PD22 